\title{
EDITORIAL
}

\section{Competencies for the 21st century professional: a look at the present and towards the future of Education}

"Revista de Medicina" reaches its 100th published volume, consolidating itself as a herald of innovative academic productions in health and education. This outstanding journal has, for over a hundred years, functioned as a space for sharing successful experiences in Medical Education, in addition to being a marker of the future paths that lead teachers and students to improve the teaching-learning relationships that aim at a better training of the students to become health professionals. This celebrated moment is an invitation to remember a successful past, but it also forces us to look to the future: what are the skills needed to train the 21 st century professional?

The term "education in the 21 st century" is based upon the central concept of the four competencies necessary for professional training in this context of innovations and great access to technology, the $4 \mathrm{Cs}$ of education: Communication, Critical thinking, Collaboration and Creativity1. Education experts, reviewing this proposal, suggested that two more competencies should be added to this framework: Connectivity and Citizenship2. The $6 \mathrm{Cs}$, therefore, constitute the group of skills that must be developed in any educational process that aims at training a professional suited to the needs and novelties of the 2000s.

The development of these competencies finds a parallel in Medical Education: the Royal College of Physicians and Surgeons of Canada created in the 1990s the educational framework called CanMEDS, identifying essential competencies in the training of physicians to provide the best possible care to the patient3. In 2015, this framework was updated. Currently, seven roles are listed: Medical Expert, Professional, Communicator, Collaborator, Leader, Health Advocate and Scholar. It is, therefore, evident that the physician for the $21 \mathrm{st}$ century has to be trained based on the skills of the $6 \mathrm{Cs}$ of education.

Faced with this scenario, "Revista de Medicina" reinforces its important role as a diffuser of knowledge, especially in the academic health sector, enabling the development of essential skills for the training of good professionals of the 21 st century, a vanguard it has occupied since 1916, when published by first time. Today, reaching the hundredth volume, it again presents a look to the future, based on scientific evidence, which recalls the qualities listed by Prof. Angelita Gama, a long-term contributor to this periodic, on the occasion of its centenary: pioneering, leadership and perseverance.

May this be an invitation to a greater recognition and diffusion of health education as a growing science. With increasing relevance in teaching and ultimately in the quality of healthcare providers, "Revista de Medicina" remains a beacon for those seeking innovation and quality. 


\section{REFERENCES}

1. Anugerahwati M. Integrating the $6 \mathrm{Cs}$ of the 21 st Century Education into the English Lesson and the School Literacy Movement in Secondary Schools. In: International Seminar on Language, Education, and Culture; 2019. KnE Social Sciences. 2019:165-71. doi: https://doi.org/10.18502/ kss.v3i10.3898.

2. Miller BS. The 6Cs Squared Version of Education in the 21st Century, June 2015. Retrieved on March 1, 2021. Available from: www. bamradionetwork.com.

3. Frank JR, Snell L, Sherbino J. Can Meds 2015 physician competency framework. Ottawa: Royal College of Physicians and Surgeons of Canada; 2015. Available from: https://www.royalcollege.ca/ rcsite/documents/canmeds/canmeds-full-framework-e.pdf

\section{Matheus Belloni Torsani, MD}

Medical Education Expert - University of São Paulo Medical School

Advisor to the Undergraduation Provost - University of São Paulo

Email: matheus.torsani@fm.usp.br 